ISSN 1984-3755

Licenciado sob uma Licença Creative Commons

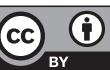

\title{
El Dios empático: la irreverencia de Edith Stein entre la fenomenología y la fe
}

\author{
An empathetic God: Edith Stein's irreverence, \\ between phaenomenology and faith
}

\section{Alejandro Bertolini*}

Pontificia Universidad Católica Argentina (UCA), Buenos Aires, Argentina

\section{Resumen}

Tomarse en serio la alteridad como constitutiva de la propia mismidad puede llevar lejos a la razón que piensa la complejidad del ser. Así al menos le pasó a agnóstica Edith Stein, quien dió sus primeros en la fenomenología centrándose en el estudio de la empatía, y terminó su existencia haciéndose carne con Aquel que intuyó como el amor crucificado. En este artículo, el autor presenta un recorrido desde la noción de Empatía como fundamento de la intersubjetividad a la potente reconfiguración de la imagen de Dios, que empático se ofrece como fundamento sólido para la verdadera comunión humana. La autora elegida, la santa filósofa del Carmelo, es ella misma un

AB: Doutor em Teologia, e-mail: alejandrobertolini@gmail.com 
emblema de la circularidad hermenéutica entre razón y fe, filosofía y teología que Juan Pablo II supo formular en FR 73-74.

Palabras clave: Edith Stein. Trinidad. Dios empático. Individuación. Forma vacía.

\section{Abstract}

Taking into consideration otherness as a constitutive part of oneness may take the reason that dares reflect on the complexity of the Being too far. At least, this is what happened to Edith Stein, who started her Philosophical life focusing on the phenomenon of Empathy and ended her existence embodying Him who she sensed as the Crucified Love. In this article, the author presents an itinerary from Empathy as the foundation of intersubjectivity to the powerful reconfiguration of God's image in terms of Empathy that empathically offers himself as a new solid foundation to real human communion. The chosen author, the Carmelite nun, philosopher and saint, is she herself a living icon of the hermeneutical circle between reason and faith, philosophy and theology, mentioned in FR 73-74 by John Paul II.

Keywords: Edith Stein. Trinity. Empathetic God. Individuation. Empty form.

"El Dios visto, escuchado y tocado en el hombre Jesús es al mismo tiempo el hombre que ve, escuch y y toca a Dios"1.

\section{Introducción}

Fontal. Arcana. Primigenia. Aquella a partir de la cual el mundo fue engendrado en razón de la creatividad, del exceso de sentido que se deriva desde siempre de la Hospitalidad recíproca. Eterna novedad, intimidad

1 VON BALTHASAR, H. U. Gloria I: La percepción de la forma, Madrid: Encuentro, 1985, 86. 
que todo lo comprende y fecunda. La empatía primordial se trasluce en el misterio del ser, se manifiesta tímida y seductora ante la mirada del que despojado de sí, sabe abrirse a la fascinante complejidad de lo real entrelazado. Pero para acceder a ella, para zambullirse en la plenitud de presencias habitadas, es menester callar la propia existencia y avanzar confiado. Urge acoger el silencio, y dejarse escribir por el Logos promisorio del Otro que, a fuerza de compasión y ternura, busca enmiarse ${ }^{2}$ hasta sitiarnos y darnos así la gracia de estar en nosotros estando en Él.

Decir una palabra desde el más allá de la Revelación cristiana también es también mostrar la profunda afinidad con el más acá de la presencia íntima y elocuente de Dios en nuestras vidas. Un balbuceo teológico, que bien entendido dice mucho del hombre y al hombre, porque todo lo que es verdaderamente humano es por esa misma y precisa razón, auténticamente religioso. Si hay algo de certero en aquello de la Gaudium et Spes (GS) "el misterio del hombre solo se resuelve a la luz del misterio del Verbo encarnado" (GS 22), entonces esta singular coreografía del espíritu que es la empatía podrá contemplarse y reconocerse en su dimensión más originaria solo en el cruce de miradas abisales que comporta la fe.

Lo cierto es que hasta el momento, no existe una teología de la empatía como tal. La Escritura no habla jamás de esta vivencia, al menos con este término. Tampoco lo hace la tradición. Y si su uso contemporáneo es fomentado principalmente por la psicología, la tarea se vuelve aún más ardua en virtud de la histórica enemistad - ya superada por suerte- entre teología y psicoanálisis.

La punta del ovillo la ofrece una judía agnóstica. Edith Stein, discípula dilecta de Edmund Husserl, ensaya su debut en la filosofía alemana de su tiempo con un trabajo sobre El problema de la empatía. Allí, en las primeras páginas de su estudio, deja caer una irreverencia que pone en jaque muchas premisas inobjetables de la filosofía universal. Feliz negligencia que anticipa, como fragmento que contiene al todo, su originalísimo derrotero intelectual, existencial y amante.

2 Neologismo del Dante para describir el proceso de inhabitación divina en el hombre. ALIGHIERI, D. Divina Comedia. Madrid: Cátedra, 1988, Paraíso, Canto IX, 81, p. 575. El original italiano dice: s'io m'intuassi come tu t'immii. Cf. también: CAMBÓN, E. Trinidad: modelo social, Madrid: Ciudad nueva, 2000, p. 40. 
La Empatía primordial que Stein vislumbra en "el frío pensar exacto a la verdad sujeto" (PEMÁN, 1997, p. 935), la arrebata de tal modo que entra en crisis hasta la conversión. Epoché verdadera ${ }^{3}$ para que emerja la presencia del que solo había intuido su reveladora ausencia. Creyendo, Edith se transfiere ella misma a Dios, y por él con él y en él percibe diverso al hombre, y diverso al mismo Dios, y otra vez, diverso al hombre. Novedad tras novedad. La circularidad hermenéutica que entabla entre razón y fe sigue el ritmo de la sabia que como sangre de la vid, alimenta y cohesiona secretamente al todo. Razón dilatada, fecundada por la Palabra, que logra ver e intuir la intimidad divina desde la empatía humana, y luego nuevamente al hombre desde la empatía divina. Desde el Dios empático. Hasta el punto de entender la relación entre uno y otro como una - valga la redundancia — : empatía transfigurada (BERTOLINI, 2013, p. 566-569).

Las novedades que surgen de este recorrido singular son muchas. Hablar de un Dios empático es, por lo pronto, una osadía reconciliadora que articula y ensambla muchas nociones que se escuchan, sí, pero no bien hilvanadas.

Cuanto digamos aquí tendrá solo carácter de promesa, en el mejor de los casos. Seguiremos este orden: en primer lugar, posaremos la atención en la irreverencia filosófica que da origen a este pasaje de lo humano a lo divino. Stein se aventura en la comprensión de la empatía y abre un paso que con el tiempo se volvió eje central del conocimiento de lo divino. En un segundo momento, consideraremos las proyecciones de la empatía a nivel humano y su repercusión en la comprensión de Dios: el pasaje ascendente de la empatía a la Trinidad. Aquí la "nueva" luz que esta categoría arroja sobre el hombre afectará felizmente en la comprensión más acabada del Dios de los cristianos. En un tercer momento, procederemos en sentido inverso: de la comprensión nueva del Dios Trino a la empatía humana.

3 Cf. E. PRZYWARA, “E. Stein und S. Weil”, en W. HERBSTRITH, Glaubenzeugnis, 1996, 231. Citado por H. HECKER en Phänomenologie des Christlichen bei Edith Stein, Würzburg 1995, 122. 


\section{La osadía inicial}

\section{La danza de la Einfühlung4: alteridad, cuerpo y verdad en sí}

Edith Stein llegó a la filosofía luego de decepcionarse profundamente por la psicología que le tocó estudiar en sus primeros años de vida universitaria. Crecida en el seno de una burguesía secularizada, la novedad de la fenomenología le resultaba estimulante por ir al fondo "mistérico" de las cosas, por trascender el mero fenómeno y bucear en las raíces de lo real.

La corriente de Husserl proponía repensarlo todo desde la nueva epistemología que representaba su aporte. Y el marco interpersonal de esta nueva teoría del conocimiento, al que el maestro había aludido ya en varios escritos, había sido solo mencionado sin ulterior profundización. Edith decide entonces a abordar el fenómeno de la empatía, comparando las diversas teorías que estaban vigentes en su época y evidenciando la agudeza del nuevo método. En medio de la ardua indagación que semejante propósito representaba, estalla la primera guerra mundial y Stein cambia su abordaje teórico por un compromiso social que le aportará la vivencia real de la empatía: se enrola como enfermera por un tiempo prolongado en un hospital de guerra en Austria. El contacto efectivo con los cuerpos sufrientes de los soldados calará hondo en su vivencia de la Einfühlung.

Al volver a la tarea académica, su visión había mutado y el abordaje teórico estará ahora sembrado de ejemplos que remiten a su experiencia del dolor ajeno. Pero no es este aspecto el que más atrapa nuestra atención, sino su descripción esencial de cuanto nos ocupa.

\footnotetext{
4 La palabra técnica que usa Stein para "empatía”. Cf. DROSDOWSKI-W. MÜLLER, G. (HRSG). Duden Etymologie: Herkunftswörterbuch der deutschen Sprache, Manheim 1989, 209. Es muy interesante el problema que ha sufrido este término tanto en las traducciones italianas como en las españolas. En italiano, se optó por entropatía, en atención al prefijo ein de este verbo sentir, que en italiano es polivalente. Cf. MANGANARO, P. Verso l'Altro, Roma: Città Nuova, 2002, p. 47. El mismo fenómeno se constata en las versiones españolas: proyección afectiva, o bien impatía, introyección sentimental, introyección afectiva, intrafección, intrasensación. Todas éstas hacen referencia a uno solo de los estadios de la Einfühlung, que es el transferirse dentro del otro (Hineinversetzung). De aquí su parcialidad. Cf.. CABALLERO BONO, J. L. "La empatía y su importancia en la vida del hombre" en SANCHO FERMÍN, F. (dir) Edith Stein, antropología y dignidad de la persona humana, Ávila, 2009, p. 101.
} 
Tratemos entonces de la empatía misma. Aquí se trata de un acto que es originario como vivencia presente, pero no originario según su contenido. Cuando aparece ante mí de golpe, está ante mí como objeto (v.g. la tristeza que "leo en la cara" a otros), pero en tanto voy tras las tendencias implícitas (intento traerme a dato más claramente de qué humor se encuentra el otro) ella ya no es objeto en sentido propio, sino que me ha transferido hacia dentro de sí; ya no estoy vuelto hacia ella, sino vuelto en ella hacia su objeto, estoy cabe su sujeto, en su lugar. Y sólo tras la clarificación lograda en la ejecución, me hace frente otra vez la vivencia como objeto (STEIN, 2002-2004a, p. 88).

Tres pasos jalonan la elipse que la empatía traza entre la consciencia ajena y la propia. El primero lo constituye la emersión de la vivencia objetiva: la distancia garantiza la trascendencia de lo vivido por el otro. El segundo momento implica una "inmersión" en la experiencia ajena, solo alcanzable por una momentánea suspensión de la propia subjetividad. El precio del nacer a la perspectiva del otro es el vaciamiento momentáneo de la propia. Negatividad, reducción o epoché imprescindibles, que dan paso y espacio al otro en cuanto otro, de modo tal que resulte evidente lo siguiente: la irreductibilidad de la otredad en cuestión exige el precio de la propia kénosis. Cierra la elipse una posterior objetivación comprensiva que supone una vuelta al propio punto de inicio, pero con la aprehensión lograda.

De todo este movimiento resulta una inhabitación de la vivencia ajena en la propia conciencia. Un rítmico entretejerse del yo y del tú, que puede fundar un "nosotros", pero que tiene siempre un valor decididamente gnoseológico. La empatía es un modo primario de conocer: desnuda y entrega una esencia que habita en la experiencia ajena. Lejos de las vagas descripciones en danza que reducen esta noción a un plano meramente emocional, en este marco intersubjetivo una verdad se abre paso.

La valencia cognoscitiva de la empatía lleva a Stein a afirmar que es esta experiencia la que garantiza la objetividad de las cosas en sí. De cara al nominalismo kantiano, la fenomenología apela a la intersubjetividad para la convalidación de la percepción subjetiva: analogía mediante, sólo la vivencia ajena aprehendida asevera que lo conocido por uno es cognoscible por el otro. De aquí que lo interpersonal se vuelve locus de la emergencia de lo que es en sí. 
Encerrado en los límites de mi individualidad, no podría salir del "mundo tal como se me aparece", siempre sería pensable que la posibilidad de su existencia independiente, que como posibilidad todavía podría darse, permaneciera indemostrada. Pero tan pronto como traspaso aquellos límites con ayuda de la empatía y llego a una segunda o tercera apariencia del mismo mundo con independencia de mi percepción, queda acreditada aquella posibilidad. Así deviene la empatía, como fundamento de la experiencia intersubjetiva, condición de posibilidad de un conocimiento del mundo externo existente (STEIN, 2002-2004a, p. 146).

Lo propio de la fenomenología consiste en distinguir entre lo originario (que brota de la propia vivencia) y lo no originario (PEZZELLA, 1995, p. 79). De aquí que Stein haga un culto de la irreductibilidad de la alteridad. Si bien la vivencia empatizada está alojada en la intimidad de la propia consciencia, la trasciende sin confundirse con ella.

Pero ¿qué garantiza, pues, que el otro siga siendo el otro y no quede subsumido en la mismidad, o bien que lo comprenda desde una proyección de lo propio? El Leib: el cuerpo viviente. En la corporalidad ajena, y en la forma de "darse" o manifestarse del "yo" que la anima reside la fuente de su irreductibilidad. Así pues:

A grandes rasgos nos hemos dado cuenta de lo que como mínimo hay que entender por un yo individual: un objeto unitario en el que la unidad de consciencia de uno y un cuerpo físico se ayuntan inseparablemente, por lo que cada uno de ellos adquiere un nuevo carácter, el cuerpo aparece como cuerpo vivo y la conciencia como alma del individuo unitario (STEIN, 2002-2004a, p. 137).

De modo que individualidad irreductible y cuerpo vivo animado son magnitudes correlativas. Stein expresa tal vínculo bajo un término sugerente: co-datitud, o manifestación simultánea de la otredad y la mismidad a partir de la percepción empática del cuerpo ajeno animado. Si el sujeto percibe desde un "punto cero de orientación" a partir de la empatía quiebra o modifica su "conciencia unitaria típica" y nace a la consideración simultánea de la pluralidad relacionada: 
En la medida en que comprendiéndolo como cuerpo vivo sensible me transfiero a él empatizando, obtengo una nueva imagen del mundo espacial y un nuevo punto cero de orientación. No es que traslade mi punto cero hasta allí, pues yo conservo mi orientación originaria. Por otra parte lo que obtengo no es una orientación de fantasía, sino que a ello corresponde cooriginariedad como a las sensaciones empatizadas, porque el cuerpo vivo al que la orientación está referida es al mismo tiempo cuerpo físico percibido por ella y porque ella está dada como originaria para el otro yo, aunque no originaria para mí (STEIN, 2002-2004a, p. 143).

Lo dado simultáneamente de modo correlativo, es la pluralidad de puntos ceros de orientación, irreductibles entre sí. De modo que es la mediación del cuerpo la que da a luz la conciencia de la diferencia, sobre la cual es posible tanto el conocimiento del otro y su vivencia, la constitución de la propia individualidad y finitud (al conocerse a uno mismo como uno entre muchos), y a la vez posibilita la convalidación de la percepción subjetiva por el diálogo interpersonal. Así el cuerpo vivo (o cuerpo vinculado según algunas traducciones al español de Leib) es condición de la empatía, y de lo que brota de ella.

\section{La irreverencia que abre el paso}

Todo cuanto hemos dicho hasta el momento tendría solo valor filosófico si pasáramos por alto uno de los párrafos más significativos y evocadores de todo el tratado. Aquí la osada Stein va más allá de su background judío y en su impostación filosófica y trasgrede una de las premisas inexpugnables de la filosofía de todos los tiempos. "Así aparece la experiencia que un yo en general tiene de otro yo en general. Así aprehende el hombre la vida anímica de su prójimo, pero así aprende también, como creyente, el amor, la cólera el mandamiento de su Dios, y no de modo diferente puede Dios aprehender la vida del hombre" (STEIN, 2002-2004a, p. 88).

Al tiempo de la redacción de este estudio nuestra autora se confiesa todavía agnóstica. Edith trabaja sobre un Dios cuya existencia es hipotética, lo que hace aún más interesante la propuesta. Su razonamiento podría parafrasearse así: de existir un Dios, éste conocería y se dejaría conocer 
por la empatía. La primera trascendencia horizontal ahora se vuelve vertical, y la otredad a considerar hay que pensarla también en mayúsculas. La fenomenología de la persona se vuelve por un momento, fenomenología de la religión y por qué no arriesgar: también adquiere visos de teología de la revelación. Porque en tanto otro, Dios no solo es sujeto activo de conocimiento empático sino que también se deja conocer de la misma manera, porque antes se manifiesta.

Todo lo cual lleva a pensar lo siguiente: para ser consecuentes con la asunción de la empatía como categoría clave de la relación con Dios y su manifestación al hombre, hay que postular también la "necesidad" de un cuerpo vivo para que este conocimiento recíproco entre el hombre y su Dios, el Totalmente Otro, acontezca (BERTOLINI, 2013, p. 55-59). Y en esto radica la osadía filosófica de la judía y agnóstica Stein: anticiparse a través de una intuición teorética a la centralidad revelatoria de la encarnación. Es claro que no puede atribuírsele semejante intelección al momento de escribir el texto, pero el razonamiento no es nada forzado en una mirada retrospectiva.

Contra el lugar común de todas las filosofías que se refieren a Dios como espíritu puro, propone la necedad y el escándalo (cf. 1 Cor 1, 20-22) de la carne divina. Con esta apuesta desde el mismo inicio de su carrera intelectual, es fácil entender los reparos que su itinerario despertó en muchos de sus colegas.

Es muy conocido el rol determinante que tuvo El libro de la vida de Teresa de Ávila en la conversión de la fenomenóloga alemana. Basta hojearlo para percibir qué tan fundamental fue para la espiritualidad teresiana la contemplación de la humanidad de Jesús. Así pues, aunque no venga de un testimonio directo de la autora, bien podemos suponer que la consideración del cuerpo humano-divino fue clave en su epoché creyente. Y también, que el período de profundo silencio que sucedió a su ingreso al cristianismo habrá representado para ella el lento acompasarse de su existencia a una empatía reconfigurante de corte trascendental y místico: la empatía de la fe en el Dios de los cristianos.

Cualquier expedición teológica en terrenos de la empatía debe partir de esta feliz y problemática osadía. La tarea es complicada, pues implica conmoverse ante la idea de un Dios que decide libremente conocernos a 
través de su cuerpo, y revelársenos en la carne del Crucificado Resucitado. No solo mostrársenos en la carne, sino aprender lo que la humanidad es a través de la vivencia apropiada de la finitud humana. Abrazar y devenir aquello que no es -creatura- para que se establezca una intimidad propia de la comunión.

Todo cuando hemos visitado nos ayuda a entender la conexión entre la empatía fenomenológica y una teología renovada por la fuerza de la carne, que transfiere análogamente las notas propias de la Einfühlung al vínculo con Dios, a la vez que allana el camino hacia la empatía primigenia. A tal movimiento nos abocamos en la sección que sigue.

\section{El nosotros entre lo humano y lo divino}

Apenas mencionado en el apartado anterior, resulta casi una obviedad el protagonismo que tiene la empatía steiniana en la construcción de la intersubjetividad. Pero esta afirmación, casi innecesaria se ve matizada y precisada por la agudeza de nuestra filósofa ahora creyente. Asomémonos por un instante al rol que reviste la empatía en el "ensamble" del nosotros humano en y desde el Nosotros divino.

\section{El fundamento de la comunidad, en dos tiempos}

En su estudio sobre el individuo y la comunidad (cf. STEIN, 20022004b), Stein desarrolla la conformación de la estructura óntica de la comunidad en torno a la recíproca apertura de los miembros que, unidos por una misma corriente de vivencias, dan "entidad" a un nosotros del todo peculiar. Así: "la tropa es el sujeto de la vivencia comunitaria que vive en nosotros, los diversos sujetos individuales que pertenecen a él. Este sujeto lo sentimos afectado en nosotros, cuando tenemos una vivencia comunitaria. Yo siento pena como miembro de la tropa, y la tropa siente pena en mí" (STEIN, 2002-2004b, p. 347). Hay un sujeto conformado por una pluralidad de individuos, que vive no en sí mismo, sino en el individuo que conoce. La relación establecida es de mutua inmanencia, 
de presencia recíproca actuante: la tropa siente en el sujeto, y el sujeto siente pena como miembro de la tropa. Notemos la gravitación de lo comunitario en la persona.

Se distingue una corriente de vivencias compartidas que recorre todos los contenidos de sentido de las vivencias individuales, y fundamenta así la unidad de la vivencia comunitaria. Así se constituye como unidad de sentido ${ }^{5}$ en y a través de los sujetos que la componen. A pesar de tener una cierta fisonomía y personalidad propia, en sentido estricto esta comunidad no goza de un yo hipostático puro. No existe el nosotros en sí, sino que "solo" acontece en y a través de sus miembros, en virtud de la apertura recíproca que transfiere esta vivencia de unos a otros a través de la empatía (STEIN, 2002-2004b, p. 361). Aseveración contundente en tiempos de totalitarismos en ascenso: al menos contemplado desde lo humano, el fenómeno asociativo depende exclusivamente de la red vincular trazada entre los sujetos que la conforman. De sus libertades y peculiaridades ${ }^{6}$, que se imbrican unas con otras. No existe un estado, una comunidad, una estructura por encima y por fuera de la empatía nacida del vis a vis.

Ahora bien, gracias a esta arquitectura del espíritu, es factible considerar la vivencia del amor. Al asomarse al núcleo del otro, es posible sentir una atracción hacia la bondad presente en él. "El ser atraído implica un impulso de entrega y unión hacia la otra persona, que en su máxima intensidad tiende a la completa unificación de la comunidad de vida y estado existencial, como lo es en el caso del amor" (STEIN, 2002-2004b, p. 478-479). Tal unificación admite diversas intensidades. Uno podría ponerse a disposición de la otra persona conservando el propio carácter. $\mathrm{O}$ bien, un grado superior consistiría en "darse tal como uno es, darse a sí mismo en propiedad, para disposición del otro, y apropiarse a su vez de

5 Cf. También Heimpel, J. Il rapporto tra la persona e la comunità nella visione cristiana di E. Stein, Roma, 2005, y A. Bertolini, Empatía y Trinidad [...], $106-120$.

6 "El ser genuino de la comunidad tiene su origen en la peculiaridad personal de los individuos. Si hubiera únicamente representantes típicos (es decir, representantes que no fueran más que tipos), entonces sería imposible el desarrollo continuo del espíritu comunitario, y no podría formarse en absoluto un espíritu comunitario. Tan sólo en la convivencia de personas individuales puede desarrollarse un tipo comunitario, en cuyas formas puedan integrarse luego las personas a quienes les falte una marcada peculiaridad personal" (STEIN, 2002-2004b, p. 472). 
la persona del otro" (STEIN, 2002-2004b, p. 478-479). Esta apropiación cruzada de disposición total, bajo el modo de la entrega, puede comprender un "abandono más o menos extenso de la propia personalidad: ya sea a favor de la manera de ser de la persona ajena o bien de una nueva forma de ser que nazca de la unión de las dos corrientes vitales" (STEIN, 20022004b, p. 478-479). Esta transformación resultante de los dos sujetos vinculados, se explica porque "el amor hacia una persona tiene la energía suficiente para sofocar en su misma raíz las mociones que lo impidan y como consecuencia, para hacer que desaparezcan también los correspondientes rasgos de carácter" (STEIN, 2002-2004b, p. 478-479). Curiosa mención de la negatividad propia del amor auténtico, que parece rescatar el movimiento de Hineinversetzung o epoché de la propia subjetividad hacia el otro, ahora asumido en el amor.

\section{El horizonte creyente y el comienzo de la inversión}

Dicho esto, no resulta anecdótico reparar en una inspiración trascendente de esta dimensión kenótica de la entrega amorosa. En Fundamentos teóricos de la labor social de la educación (1930), en una conferencia a educadoras católicas, la todavía laica Stein afirma con certeza:

Que el hombre según su naturaleza sea miembro del gran cuerpo de la humanidad, nacido de la comunidad en y para la comunidad, es un hecho, pero un hecho misterioso, un hecho que está relacionado con todos los misterios del cristianismo y recibe luz de ellos, pero que por eso no es enteramente penetrable por la luz de nuestro entendimiento natural. Lo podemos seguir aun dando un paso adelante en lo alto y en lo bajo hacia lo más profundo, hasta su raíz en el misterio más alto y último de la fe: el misterio de la Trinidad. Dios creó al hombre a su imagen. Pero Dios es uno entre personas. ... Una esencia indivisible, completamente simple y única en su ser: es decir, individuo en el sentido más perfecto de la palabra. Pero una esencia que es al mismo tiempo tres personas que se ligan en unidad de ser y de vida en conocimiento, amor y obra: es decir, comunidad en el sentido más perfecto de la palabra (STEIN, 2002-2004c, p. 131). 
Stein ha dado un paso rotundo, que antes no quedaba del todo explícito. Hay un Dios que es al mismo tiempo perfecto individuo y perfecta comunidad, y es este el misterio que explica la capacidad de asociarse el hombre y realizarse simultáneamente como individuo y como comunidad, es decir: como persona. Lo que no tenía consistencia en sí fuera de la comunión empática: el nosotros humano, transparenta ahora un sustrato teológico y ontológico contundente: el Nosotros divino.

Ahora bien, ¿habla aquí de la empatía como núcleo de la vida trina? De eso nos ocuparemos más adelante. Queda por relevar en el pensamiento de la santa carmelita otra relacionalidad constitutiva con su fundamento trino: la diferenciación sexual.

La antropología de Stein es decididamente diferencial o dual. Consecuente con su impostación fenomenológica, no puede considerar al hombre como entidad de razón, sino a partir de su constitución psicofísica. Y en los hechos, la esencia hombre solo se conoce en su concreción varón o mujer. La diferenciación sexual afecta no solo a la materia, sino que configura el plano psíquico y ontológico (cf. CASTILLA DE CORTÁZAR, 2004). Y esto es así porque está hecho a imagen y semejanza de un Dios que es uno, pero a la vez diferente y plural:

Porque no hubiese sido bueno para él estar sólo, es cosa que de nuevo hay que explicar a partir de la Palabra de Dios. Dios creó al ser humano y su imagen. Pero Dios es uno y trino, así como del Padre procede el Hijo y del Hijo y del Padre el Espíritu, así también la mujer ha salido del hombre y de ambos la descendencia. Y además, Dios es amor. Pero con menos de dos no puede existir el amor (STEIN, 2002-2004d, p. 275).

Otra sutil osadía: en la historia del pensamiento cristiano, por razones múltiples, la imagen del Dios trino fue siempre relegada a la vida intrasubjetiva (la analogía psicológica agustiniana). La unión sexual, de la cual todos provenimos, estaba a años luz de gozar de esta iconicidad trinitaria. Pero Stein da el paso que ni Tomás ni Buenaventura, ni Ricardo de San Víctor se animaron a dar: 
Para las almas es posible una aún más íntima unidad, ya que en la vida espiritual se da una unión que no encuentra su semejante en el campo del ser corporal: la imagen creada del amor entre el Padre eterno y el Hijo divino. Evidentemente, entre las criaturas cada una tiene su propia esencia, no una sola común como la de las personas divinas; pero las almas humanas pueden abrirse mutuamente en virtud de su libre condición espiritual, y en el don del amor una puede acoger a la otra en sí misma (STEIN, 20022004e, p. 430).

En razón de la unión espiritual que se logra en la intimidad conyugal, la atribución de la imagen trina al vínculo matrimonial es posible. El sentido del paso trasciende la materialidad de la carne que en otras épocas — veladamente dualistas — había bloqueado la fecunda asociación entre amor humano y amor divino. De esta manera, si al comienzo de nuestro itinerario la fundamentación de lo comunitario consistía en la misma empatía humana, ahora la raíz parece remontarse a lo más alto y a lo más profundo y engarzarlo en la comunión trina.

Aunque dos de las formas básicas de interpersonalidad, la nupcial y la comunitaria, son referidas a su fuente divina y trascendente ${ }^{7}$, la matriz empática se puede vislumbrar, pero no está explicitada. La conexión directa con lo trinitario puede apreciarse en lo que sigue.

¿Cómo y dónde concibe Stein la Trinidad in recto? La opera magna de la santa carmelita, Ser finito y ser eterno, puede ser vista como una pequeña suma filosófico-teológica, en la que todo trascurre en pos de dilucidar el sentido más primigenio del ser ${ }^{8}$. Al cierre del capítulo VI, donde este ascenso llega a su cumbre, encontramos estas definiciones por demás elocuentes:

Pero frente al yo finito está un tú, como otro yo, como su igual, como un ente al que se puede dirigir reclamando entendimiento y respuesta y con el que el yo, fundándose en la igualdad del ser de la que vivenciamos el ser uno de la pluralidad de personas. El ser uno no suprime la multiplicidad y la diversidad de las personas. La diversidad es ante todo una diversidad del ser, como hemos reconocido que ella pertenece a la esencia del yo, el

\footnotetext{
7 Stein no se pronuncia sobre otros vínculos al menos hasta este momento. Luego, más adelante, referirá toda forma de intersubjetividad a la matriz kenótico-perijorética de la intimidad trina.

8 De hecho, el subtítulo reza: “ascenso al sentido del ser" (Versuch eines Aufstiegs zum Sinn des Seins).
} 
estar articulado en una unidad no suprime la unidad monádica de la vida del yo. Pero existe enseguida una diferenciación de la esencial. La comunidad específica que sirve de fundamento al ser nosotros deja un espacio para una manera de ser personal que el yo no comparte con nadie. Tal diferenciación de la esencia no debe ser tomada en consideración cuando se trata de las divinas personas (STEIN, 2002-2004e, p. 943).

Como era de esperar, el abordaje es antropológico. La circulación hermenéutica entre razón y fe, tal como la propone Juan Pablo II en FR 73-74, es constatable. En el primer tratamiento in recto del misterio trinitario, el punto de partida es el vis a vis personal, en simultánea unidad y distinción sustancial. La insistencia en la diferenciación de "hipóstasis" es importante, porque pone de manifiesto que la empatía, celosa de las peculiaridades irreductibles de aquellos que se reconocen, opera a modo de forma mentis para cuanto sigue y se anuncia como clímax de todo el argumento:

Y sin embargo, es posible la distinción del yo y del tú, sin la cual ningún nosotros es posible. Junto a la manifestación del nombre divino "Yo soy", se encuentra en el AT esta fórmula a propósito de la creación: "hagamos al hombre a nuestra imagen", que nuestros teólogos interpretan como la primera alusión al misterio de la Trinidad: conviene también notar las palabras claras del salvador: "mi Padre y yo somos uno" (STEIN, 20022004e, p. 943).

Stein repara en la "distinción" sin la cual la unión es inviable. Afirmación sorprendente y saludable, cuya originalidad destaca en tiempos en que la trinitariedad del Dios cristiano estaba aún a la sombra de una unidad de sesgos monolíticos y sustancialistas (ZARAZAGA, 2004, p. 253-281). Hasta mediados del siglo XX, la interpersonalidad y la pluralidad divina fueron una verdad del dogma sin demasiado impacto en la cosmovisión de la fe. De lo que se sigue el carácter pionero, avant la lettre de esta "teóloga sui generis", que confirma esta afirmación personalista en grado eminente: "puesto que Dios es amor, el ser divino debe ser el ser uno de una pluralidad de personas y su nombre Yo soy equivale a "yo me doy enteramente a un tú" y por lo tanto, también con un "nosotros somos" (STEIN, 2002-2004e, p. 943). 
La equivalencia establecida entre el Yo soy y el Nosotros somos, paradojal por donde se la mire, solo se resuelve en la entrega kenótica que articula los dos extremos de la proposición. La entrega es hacia el otro, orientada hacia la otra persona. El don de sí adquiere rango ontológico, y todo esto es posible por la matriz empática que opera de fondo. Un cara a cara, una intimidad arcana y primordial que se muestra como la fuente de toda fecundidad. Reinterpreta la ontología clásica al releer la piedra fundamental de la metafísica del Éxodo: Ego sum qui sum (GILSON, 1948, p. 39-62) y la transforma en una ontología de la persona. Según P. Coda: «no se trata de aniquilar o abandonar la sustancia sino de introyectar la dinámica de la relación, y no de cualquier relación sino de aquella ritmada trinitariamente- en la determinación del ser en sí» (CODA, 2008, p. 19).

La Denkform personalista de su teología es tan marcada, que podemos encontrar muchos de los rasgos propios de la empatía primera, ahora transfigurados. A partir de entonces, lo que se diga de la vida trina será también una conquista sobre el sentido del ser como amor. Así pues, dirá: «El amor, en cuanto vida divina íntima, no puede ser sustituido por el amor entre Dios y las criaturas, porque esto no puede nunca ser la mayor en su suprema perfección (aún si se piensa en el amor alcanzado por la criatura en su perfección, es decir, en su estado de gloria). El amor supremo es un amor recíproco y eterno» (STEIN, 2002-2004e, p. 947). O bien: «La vida íntima de Dios es el amor recíproco enteramente libre de todas las criaturas, inmutable y eterno de las personas divinas entre sí» (STEIN, 2002-2004e, p. 948).

Para precisar aún más el contenido de esta entrega recíproca, avanza hacia una formulación más aguda: «Lo que se entrega recíprocamente es una única, eterna e infinita esencia que abraza perfectamente a cada una de ellas y a todas juntas» (STEIN, 2002-2004e, p. 948). Llama la atención el lenguaje para hablar de la esencia divina. Una esencia que abraza, es una esencia amante, libre. Y aunque se dé una sinestesia impropia entre el orden de la esencia y el personal, una verdadera impertinencia semántica, el recurso es efectivo. Nada de lo que hay en Dios escapa a la donación personalísima del amor. Es parte del misterio, que a estas honduras hace estallar al lenguaje siempre pensado desde un horizonte limitado y finito. 
La esencia son el Padre, el Hijo y el Espíritu Santo. Las distinciones son siempre de razón. Aquí queda naturalmente más claro:

El Padre lo ofrece, desde toda la eternidad, al Hijo, en cuanto que lo engendra, y mientras el Padre y el Hijo se dan el uno al otro, el Espíritu Santo procede de ellos, como su amor recíproco y entrega. Así, el ser de la segunda y tercera persona es un ser recibido, pero no es un ser que haya nacido, como el ser creado, es el ser único de Dios que es a la vez dado y recibido, el dar y recibir pertenece al ser divino mismo (STEIN, 2002-2004e, p. 948).

Estupenda acentuación de la receptividad del Padre, quien en la tradición clásica fue siempre la fuente de donación, fácilmente asimilable al esquema patriarcal donde la autoridad provee siempre, sin simetría posible. Aquí la entrega es recíproca, y la radicalización de los rasgos personales vuelve a traer la noción de empatía como matriz que permite la comprensión más nítida de esta comunión intradivina.

El ser como don y salida de sí, que al verterse en el otro se actualiza como ser personal en su acepción más primaria, parece seguir aquella primera elipsis hacia la primera trascendencia, la horizontal, que Stein despuntaba en su primer tratado. Lo propio del ser espiritual es comunión personal y dinamismo ontológico. La identidad personal es proporcional al juego de entregas: el ser en sí se resuelve en el ser hacia el otro:

Hemos definido lo espiritual como lo no espacial, y lo no material, como lo que posee un interior en un sentido completamente no espacial y permanente en sí, en cuanto sale de sí mismo. Este "salir de sí" le es de nuevo esencialmente propio, no como si no tuviera un "en sí", sino porque entrega enteramente su él mismo sin perderlo, y en esta entrega se manifiesta enteramente- en contraposición a la soledad anímica. (STEIN, 20022004e, p. 956).

Hasta aquí llega el movimiento ascendente que hemos trazado, desde lo empático hasta la intimidad trina. La fundamentación del orden creado en Dios, no sorprende tanto cuanto la posibilidad de referirnos a él con un término "contemporáneo" como empatía. En el apartado que sigue, el parentesco vislumbrado encontrará ya un fundamento sólido en categorías propias de la tradición teológica patrística y contemporánea. 


\section{Perijóresis: la empatía primordial}

Su recíproca y personal imbricación interna de las personas divinas en Dios sugiere la analogía con la Einfühlung. En ambas se asiste a la ruptura de la inmanencia de los enlazados, en ambas se constata una cierta hospitalidad que permite el alojamiento recíproco y la plenitud de la verdad que emerge de esta comunión mutua. El texto que sigue es un punto de convergencia importante:

En la entrega total de sí de las personas divinas, en la cual cada una se enajena enteramente de su esencia y sin embargo, la conserva perfectamente, cada una está enteramente en sí misma y enteramente en las otras, tenemos ante nosotros el espíritu en su realización más pura y perfecta. La divinidad trina es el verdadero reino del espíritu, simplemente lo supra terreno. Toda espiritualidad o capacitación del espíritu por parte de las criaturas significa una "elevación" en este reino, aunque en sentido diferente y de diversas maneras (STEIN, 2002-2004e, p. 956-957).

Este dinamismo de desapropiación de la esencia y de su paradójica conservación, que incluye la mención de la inhabitación cruzada, es tanto fenomenológico como teológico. Ambas cosas a la par. Lo que Edith atribuye al espíritu en su realización más pura y perfecta es lo que los padres de la Iglesia encontraron en la categoría de perijóresis o circumincesión ${ }^{9}$ : el mutuo éxtasis de amor que permite pensar la unidad en la trinidad y la trinidad en la unidad, cada vez que se considera a las personas no tanto desde sus relaciones de oposición sino desde su inmanencia recíproca. Proveniente de la física estoica (DISANDRO, 1984, p. 441-447) que entendía a este tipo de mezcla como aquella en la que nos perdían las notas de los elementos unidos, fue asumida por primera vez para hablar de la compenetración entre la humanidad y la divinidad en Cristo (EGAN, 1994, p. 83-93). De allí pasó a la "patria trinitaria" (FORD, 1986, p. 2024), y desde entonces se implementó como el modo exacto de comprensión del misterio más arcano. Marginada durante siglos por una teología

9 Cf. DEL CURA ELENA, S. "Perikhoresis" en X. PIKAZA - N. SILANES (DIR), EI Dios Cristiano: diccionario teológico, Salamanca: Secretariado Trinitario, 1993, 1086-1094.

Rev. Pistis Prax., Teol. Pastor., Curitiba, v. 8, n. 2, 211-243, maio/ago. 2016 
que prefería pensar más la unidad que la pluralidad, hoy vuelve a su protagonismo neurálgico en auxilio del modo preciso de comunión en Dios: si la comunión de la que se habla en Dios no es perijorética, entonces no es comunión (cf. GRESHAKE, 2001).

Descripta en sus notas esenciales, la perijóresis logra no solo la ruptura de la primacía sustancialista en el pensar teológico, sino que también alumbra el entramado de lo real a modo de "nuevo trascendental" o "trascendental abierto": dado que Dios, desde un punto de vista lógico es perijóresis de identidad y diferencia, todo lo que es, en la medida que es, es perijóretico. Dicho de otro modo: está radicalmente entrelazado con la creación y con su Dios. El tratamiento que Colin Gunton hace de esta cuestión es tremendamente sugerente (cf. GUNTON, 2005).

La contracara de la recíproca inhabitación es la kénosis intratrinitaria. Dimensión de vaciamiento y negatividad cruzada que funda la posibilidad de este dinámico vivir uno en el otro. Proyección hacia la intimidad divina del himno cristológico de Filipenses (Fil XXX), ha conocido gran desarrollo en la tradición oriental y hoy es la otra clave de bóveda para comprensión del Dios comunión.

Es propiamente aquí donde radica la posibilidad verdadera de asociar, en un sentido descendente, la Trinidad con la intersubjetividad. Pero en virtud de la circularidad hermenéutica que vertebra nuestro discurso, hemos de visitar brevemente otra cuestión cara a la fenomenología: la individuación. ¿Cómo dar cuenta de la legítima irreductibilidad y peculiaridad del singular concreto ante el universal que lo comprende de modo abstracto? ¿Cómo hacer para que la histórica tensión de occidente entre lo uno y lo múltiple no se resuelva ya de modo fagocitante para lo singular? $¿$ Es factible comprender el valor positivo de lo singular sin desmedro del todo? A todas estas preguntas incisivas, Stein responde con su original propuesta en torno a la individuación. No podemos agotar su tratamiento aquí, sino solo abordarlo como fundamento del último paso que nos interesa: evidenciar a la Trinidad como la empatía primordial, arquetípica y fundante. Llegar a las mismas fuentes teológicas del fenómeno que motivó a esta santa. 


\section{Hacia una ontología de la interpersonalidad: la forma vacía y la individuación}

El aporte fundamental de nuestra pensadora a este problema de siglos consiste en el recurso a una categoría proveniente de la lógica formal husserliana, y su ulterior aplicación analítica a la Trinidad: la forma vacía. Debemos primero esclarecer brevemente qué debemos entender por ella y su vinculación con la individuación. El camino es teoréticamente arduo, pero vale la pena el esfuerzo ${ }^{10}$.

En la síntesis de Stein, el valor de lo singular brota de la consideración de una polaridad inescindible entre lo que ella llama la forma vacía y la llenura cualitativa. La primera alusión a este tema la encontramos en Potencia y Acto, en el contexto del capítulo II: la explicitación del marco ontológico formal que usará para asumir los principios de la metafísica clásica.

Con estilo pedagógico, comienza haciendo un recuento de los tipos de formas que ya se conocen: las formas visibles, la forma como coprincipio hilemórfico que configura la materia indeterminada, las formas puras o separadas que no cualifican materia alguna, pero existen en sí. Por contraposición, dirá: «En todos estos significados la forma es algo cualificado, y en este sentido es algo lleno de contenido o algo material» (STEIN, 2002-2004f, p. 259). De esto inferimos claramente que la forma vacía no comparte esta nota cualificante. Lo confirma de inmediato: «Pero tratamos de las formas en el sentido de la ontología formal sólo cuando vaciamos estas formas de su contenido» (STEIN, 2002-2004f, p. 259). Adelanta así su carácter de oxímoron: es una forma que no forma ni cualifica. Tenemos aquí el primer elemento de su noción.

\footnotetext{
10 Seguiremos los siguientes artículos: ALFIERI, F. “II 'principium individuationis' e il fondamento ultimo dell'essere individuale. D. Scoto e la rilettura fenomenologica di E. Stein”, en M. SHAHID-F. ALFIERIS (Eds.), II percorso intellettuale di Edith Stein, Bari, 2009, 209-259; Id., "Il principio di individuazione nelle analisi fenomenologiche di Edith Stein e Hedwig Conrad-Martius. II recupero della filosofia medievale" en Ales Bello, A., ALFIERI, F.; SHAHID, M. (Eds.) Edith Stein, Hedwig Conrad-Martius. Fenomenologia, metafisica, scienze, Bari, 2010, 143-197. Ver también BERTOLINI, A. Empatía y Trinidad... 215-243, Id. "Aportes para una ontología trinitaria de la intersubjetividad" en Lateranum 78 (2012) 407-447; y BETSCHART, C., Unwiederholbares Gottessiegel. Personale Individualität nach E. Stein, Friederich Reinhardt Verlag, Basel 2013.
}

Rev. Pistis Prax., Teol. Pastor., Curitiba, v. 8, n. 2, 211-243, maio/ago. 2016 
Lo cierto es que la observación comienza por la realidad concreta: «las formas vacías de ninguna manera se presentan como formas vacías, sino siempre llenas de su contenido, por otra parte cada contenido se presenta en una forma» (STEIN, 2002-2004f, p. 263). Entonces, lo que se debe hacer para dar con ellas no es un proceso de conceptualización sino más bien de abstracción. «Abstrahere es decir, en nuestro contexto, primero negativamente: carencia de plenitud. Segundo: poner de relieve la forma. Las dos cosas suceden en lo que es: plenitud y forma tienen su puesto en el ente mismo» (STEIN, 2002-2004f, p. 260). Exige, pues, un corte, escisión o reconocimiento de la plenitud en tanto separada o ausente. Y un evidenciar la forma en sí misma, en distinción lógica con su contenido.

La tercera palabra clave para cerrar la noción es individuación. Dice líneas arriba que «lo que sale a nuestro encuentro en la experiencia son los objetos determinados en cuanto contenido, sean materiales o espirituales. De tal manera determinado que cada uno se diferencie del otro: aunque sea sólo por su posición espacial o temporal. A su unicidad e irrepetibilidad la llamamos individualidad» (STEIN, 2002-2004f, p. 260). A la llenura que está unida, la llamamos concreción. Quitándola, tenemos como residuo de esta abstracción la forma vacía. Lo que individua en última instancia al ente, en correspondencia con su llenura. En Ser finito resume su función de modo tan claro que casi no necesita comentario:

La separación de forma y de contenido pertenece al ser finito en cuanto ser delimitado objetivamente. La forma vacía es la línea objetiva de delimitación que permite al ser separarse exteriormente de otros (en cuanto es él mismo) y ordenarse interiormente como una estructura de partes constitutivas diferentes objetivamente. La forma vacía del ente independiente es la del objeto, (en sentido estricto), o la del soporte del quid y del ser (hypostasis-subsistens) (STEIN, 2002-2004e, p. 950).

Según lo expuesto, la forma vacía tiene dos funciones. La primera es de orden interno en cuanto elemento imprescindible del constructo ontológico en su ultimidad: y en esto es equivalente a lo que la tradición llamaba suppositum. La segunda es externa: asume la diferenciación respecto de otro ente, en cuanto línea objetiva de delimitación. 
Dado que el centro de interés de Stein fue siempre la persona, lo que sigue se circunscribe a ella. La determinación individual de la persona acontece "geográficamente" en el Kern (STEIN, 2002-2004g, p. 310), el núcleo inasible de la persona, donde el modo de captación consciente de tal profundidad involucra una suerte de inteligencia sentiente, (el Fühlen), por la que el sujeto que se conoce lleva adelante una verdadera intuición eidética de su propia ultimidad: «la forma vacía que coloca el objeto (de conocimiento: en este caso el sujeto) sólo como sustrato de determinaciones, dejando abierta la cuestión del carácter de su contenido entendido como un en sí del todo determinado» (STEIN, 2002-2004f, p. 335). Esta forma vacía no es otra cosa que un sustrato cualitativo bien determinado que debe ser llenado mediante continuas intuiciones individuales ${ }^{11}$.

Lo que se percibe es una singularidad unida a la interioridad del ser de la cual brota, que en conjunto caracterizan totalmente a quien (se) sondea. Al entrar en esta nueva región del ser, percibe su ser plenamente sí mismo y, al mismo tiempo se distingue de la cualidad de ser de los demás. Aun así, con toda esta meritoria precisión, ha de salvaguardarse la inefabilidad de esta peculiaridad íntima. De aquí que de a ratos Edith prefiera usar la imagen simbólica de fuente o manantial interior para referirse a la vida que brota de sus honduras. Es en este manantial que el Einzelsein (singuralidad) vive anclado en su más completa soledad.

Éste es el terreno fundante de la antropología steiniana, el corazón de la base onto-metafísica de la singularidad que es precisamente la forma vacía: «es la forma específica del ser humano, aquello que lo cualifica a partir del interno en cuanto ser humano [...] en su totalidad tiene una impronta cualitativa individual [...] que se acrecienta con la intensidad

\footnotetext{
11 Es lo que se percibe en razonamiento que bien podemos llamar "argumento ontológico steiniano". Enfocado a la percepción del Ser a partir de la propia nada, muestra un ejercicio profundo de esta inteligencia sentiente que percibe la propia ultimidad: "Mi ser, tal como yo lo encuentro y tal como yo me encuentro en él, es un ser nulo; yo no existo por mí mismo y por mi mismo nada soy, me encuentro a cada instante ante la nada y tengo que recibir el don del ser momento a momento. Y sin embargo, este ser vano o nulo es ser y por eso toco a cada instante la plenitud del ser [...] En mi ser me encuentro yo con otro ser que no es el mío, sino que es el sostén y el fundamento de mi ser que no posee en sí mismo ni sostén ni fundamento" (STEIN, 2002-2004e, p. 665.667).
}

Rev. Pistis Prax., Teol. Pastor., Curitiba, v. 8, n. 2, 211-243, maio/ago. 2016 
de su propio ser» (STEIN, 2002-2004f, p. 515.519). La plenitud cualitativa del ser llena la "forma vacía" de tal modo que "sólo es advertido en la medida en que cada individuo se siente a sí mismo, como él mismo en cuanto él mismo es» (STEIN, 2002-2004f, p. 520). Si un sujeto en su unicidad, aun distinguiéndose de los demás, conserva en sí "algo" que lo vuelve un sí individual, lo que subyace es aquello que la ontología formal da en llamar formas de ser completamente vacías (Leerformen): último estadio que determina la singularidad del individuo. La afirmación es rotunda, contundente, al punto de decir sin ambages que «El individuo es (una) forma vacía. Forma vacía significa, que esta forma designa con su completo "relleno" un qué singular, y viceversa: que sólo un qué singular puede ser su relleno inmediato. Por otro lado, sólo puede ser colmada por cosas singulares» (STEIN, 2002-2004f, p. 585-587). La diferenciación exterior es posibilitada sólo a partir de ésta interior.

\section{La intimidad trina: matriz arquetípica de empatía}

Hasta aquí, un breve desarrollo de la versión steiniana del principio de individuación en el orden de lo creado. Ahora resta preguntarnos por el arraigo trinitario, si lo hubiera, de tal principio.

Lo que se dice en última instancia del hombre - el individuo es forma vacía-, mutatis mutandis, ¿puede aplicarse a Dios? ¿es Dios forma vacía? O bien: ¿hay forma vacía en Dios? Para Stein la respuesta es afirmativa aunque debamos, en atención a la consabida distancia ontológica, cribar el lenguaje en un proceso "pascual" a través lo analógico. Dicho esto, explica:

El yo divino no es un vacío, sino que él contiene en sí, abraza y domina toda la plenitud. Su perfecta unidad se expresa mejor todavía en una lengua en la que Yo soy se reduce a una palabra única: esto es el sum latino. En el Yo, en el que el ser es la vida, podemos mejor captar esta verdad: que yo y vida o ser no son dos cosas diferentes, sino son inseparablemente uno: la plenitud del ser está formada personalmente. Forma, en contraposición a plenitud, tiene el sentido de forma vacía, no de forma esencial (que es ya una plenitud formada). Pero aquí, en el origen de todo ser, tampoco 
esto es una contraposición. El infinito, esto que abraza todo, abraza y delimita a sí mismo, mientras que en el finito la forma es la delimitación de un contenido y otro, en este caso el yo significa simultáneamente forma y plenitud, el ser que se posee y se domina totalmente.[...] En el Yo soy de Dios, están todas las determinaciones trascendentales prefiguradas sin separación (STEIN, 2002-2004e, p. 943).

El texto contiene más de cuánto nos preguntábamos. Lo cierto es que confirma la posibilidad de usar esta categoría, de modo eminente. Porque es aquí donde el ser y la vida se dan inseparablemente, en donde la plenitud del ser es personal. Aquí es donde con más razón, la forma vacía podría ser dilucidada. Luego marca la diferencia elemental entre su función individuante aplicada en lo creado y "delimitante" de la plenitud sin fin de Dios. Al inicio del capítulo VII el título del primer apartado nos recibe anunciando la síntesis intuida: Hipóstasis y persona. Dice en sus primeras líneas:

La búsqueda del sentido del ser nos ha conducido al ser que es autor y arquetipo de todo ser finito. Él se revela a nosotros como el ser en persona y más aún, como el ser en tres personas. Si el Creador es el arquetipo de la creación, ¿no se debe encontrar en la creación una imagen, aunque lejana, de la unidad trinitaria del ser originario? Y por lo tanto ¿no sería posible llegar a la comprensión más profunda del ser finito? (STEIN, 2002-2004e, p. 951).

Ésta es exactamente la clave de lo que conocemos hoy como ontología trinitaria ${ }^{12}$. El impacto del dogma de los dogmas, lo específico del cristianismo en la cosmovisión de lo real. En este caso preciso, nos interesa la articulación entre forma vacía y Trinidad. Edith nos conduce a ello con lucidez penetrante, haciendo un breve racconto del influjo de la teología inmanente en la formación de los conceptos filosóficos de hipóstasis y persona. "Gracias a estos conceptos se ha adquirido algo esencial no sólo para la inteligencia de la revelación de Dios en tres personas, sino también para la comprensión del ser humano y en última palabra, lo realcósico» (STEIN, 2002-2004e, p. 941). La última aclaración nos permite trascender el ámbito de lo antropológico y extender parte de este análisis

12 Cf. HEMMERLE, K. Tras las huellas de Dios. Ontología trinitaria y unidad relacional, Salamanca: Sígueme, 2005. También: CODA, P. Dalla Trinità. L'avvento di Dio tra storia e profezia, Roma: Città Nuova, 2011, 553-593. 
hacia una ontología de todo lo creado, algo que los poquísimos autores que hasta el momento han hablado de ontología trinitaria en Stein no han señalado ${ }^{13}$.

Volviendo al argumento, apela a Agustín como el primer punto de referencia ineludible. Rescata los datos de su teología de las relaciones trinitarias, y sigue con atención los meandros de su evolución semántica. Luego de señalar la dificultad que tenemos para captar las diferencias en las Personas.

Si ponemos la diferencia de las personas en sus "relaciones" entonces tenemos que pensar que esta palabra relaciones no significa aquí lo mismo que para las cosas finitas. Agustín trata de aclarar esta dificultad mostrando que las relaciones en la Trinidad no son ni sustancia ni accidente. No son sustanciales, porque todo lo que se dice de Dios sustancialmente (es decir, como perteneciente a su esencia) -y esto fuera de todas las relaciones- vale para las tres personas y para cada una sin consideración de las otras. (STEIN, 2002-2004e, p. 951).

Atenta al salto analógico cuya omisión puede generar confusiones, introduce la gran novedad de Agustín al despegar la relación del campo accidental. "Así es necesario distinguir de la sustancia (aquí oủoí $\alpha=$ essentia) la hipóstasis en cuanto su soporte. A la unidad de sustancia se contrapone una trinidad de soportes» (STEIN, 2002-2004e, p. 952). La noción de suppositum, cara a la metafísica tomista, será la clave de bóveda para articular la equivalencia con nuestra categoría ${ }^{14}$.

Precisará luego la ambivalencia de la persona para designar las distinciones entre el Padre, el Hijo y el Espíritu. «Pues, aquí nos encontramos ante tres personas que poseen en común todo su quid y de las que ninguna es posible sin las otras, y las tres no son más que una sola: la perfección infinita, propia de cada uno y que no puede ser aumentada»

${ }^{13}$ Cf. OTTO, E. Welt, Person, Gott. Eine Untersuchung zur theologischen Grundlage der Mystik bei Edith Stein, Vallendar-Schönstadt, 1990, 145-149; KRIENKE-N. SALATO, M. A proposito di ontologia trinitaria. II contrituto di A. Rosmini ed Edith Stein per una fondazione in chiave teosofica e fenomenologica della filosofia cristiana en Rassegna di teologia 49 (2008) 227-261.

${ }^{14}$ Cf. S.th., I q. 11, a. 3. 
(STEIN, 2002-2004e, p. 952). Por esta razón, Él es persona pero en grado eminente.

Si no es "persona" ¿podrá usarse "hipóstasis" para referirse al Padre, Hijo y Espíritu Santo? Edith se muestra reacia, pues si bien reconoce su amplia recepción en la tradición teológica, su horizonte hermenéutico es tan fenomenológico que también en Dios prefiere adentrarse hasta el último estrato divisable. Dado que Tomás también aplica a Dios el nombre de "hipóstasis" sin identificarlo con persona, vinculará esta noción con la substancia, reemplazando la clásica asociación substancia = essentia por un objeto que en cuanto es subsistente por sí mismo pertenece al género de la substancia. «subjectum vel suppositum quod subsistit in genere substantiae $»^{15}$. Si uno se ajusta estrictamente a la noción de hipóstasis, no se debería llamar así a las personas divinas, pues no soportan accidentes. Pero resulta aceptable en el sentido de subsistencia, que se corresponde bien a la realidad tripersonal. Aunque, sigue con las precisiones minuciosas, <<se debe observar en qué sentido habrá de comprenderse subsistere: lo que es en sí mismo y no en otro» (STEIN, 2002-2004e, p. 955), aunque no sea justo hablar de autonomía en Dios, pues las personas son en sí mismas, en las otras. De aquí que prefiera la noción de soporte o suppositum ya presentada:

Pero la palabra soporte (Träger) ya ha sido empleada en dos significados que no coinciden con el sentido aquí exigido: la cosa ha sido llamada el soporte de una naturaleza general y el soporte de sus cualidades. Ninguno de estos significados se puede aplicar a las personas divinas, no existen en ellas cualidades (distintas de la esencia) y la esencia divina no es una "naturaleza universal" que se individualiza en las personas, sino algo singular y único que les es común. Lo que es "soportado" es la esencia una divina, indivisible, y las personas constituyen sus soportes. Esta noción de soporte de esencia me parece muy significativa para la estructura de todo ente (STEIN, 2002-2004e, p. 955).

Luego de estos rodeos necesarios, finalmente comenzamos a comprender su asociación. La noción de forma vacía es conectada al suppositum:

15 Cf. S.th., I, q.29, a.2. 
es decir, aquello que las personas divinas tienen de común entre sí, que no es esencia divina y que no hace a la distinción, y que en definitiva es la última estructura que "determina" el ser divino - es claro que el lenguaje se resquebraja a medida que se profundiza el análisis — La esencia divina es sostenida y "contenida" simultáneamente por estos tres soportes, que son la realidad más analogable con la estructura de cada ente. Soporte de esencia.

Hay una realidad ineludible: el abordaje steiniano tiene matriz fenomenológica y antropológica. La forma vacía como categoría, fue acuñada en el ámbito de la ontología formal husserliana, nunca referida -por definición- a las realidades divinas en primera instancia. Es necesario entonces una "pascua del lenguaje", respetuosa de la diferencia ontológica. No se podría, por ejemplo, aplicarla sin más a Dios, suponiendo que la persona en la Trinidad es una forma vacía que individua una esencia universal. No. Tampoco puede argüirse que haya diferencia de contenidos, como con los espíritus creados. En este sinuoso esquivar riesgos Edith hace la aplicación más directa de la categoría a lo trinitario: «la espiritualidad, la unidad, y la simplicidad de la esencia divina no dejaban otra cosa que un soporte totalmente desprovisto de materia y de contenido, un soporte que no es más que soporte, en cuanto forma vacía de la plenitud esencial» (STEIN, 2002-2004e, p. 955). Es la máxima similitud admitida, antes de desarrollar la desemejanza propia de todo momento analógico. El acento está puesto en la desnudez y vacío de este soporte, el cual es sólo eso. Soporte. Notemos cómo no hay referencia a la cantidad de soportes, sino que se habla genéricamente de los tres. Sólo así es posible lo que sigue en cuanto forma vacía de la plenitud esencial. Así, delimita claramente el modo en que puede hablarse de "persona trinitaria" como "forma vacía"; genéricamente. Y esta generalidad es la propia del arquetipo. Sigue:

Hemos llegado a esta forma vacía del soporte por conexiones completamente diferentes. El "yo puro" nos ha parecido ser como "soporte" del contenido de la vivencia, la persona (finita) como soporte de su particularidad, la forma de la cosa como soporte de su llenura de contenido y en la concepción más general del ente en cuanto tal el "objeto" o el "algo" como nos ha parecido como el soporte del quid y del ser (STEIN, 2002-2004e, p. 955). 
Siempre en el plano lindante con una ontología formal -propio del diálogo fenomenológico que sirve de telón de fondo- la noción de forma vacía comparte la característica de soporte en diversos ámbitos de las ontologías regionales. En lo trascendental, presente ya en su disertación doctoral, el yo respecto de la vivencia. La cosa con su llenura de contenido, el "universal" algo con su quid y ser. El señalamiento no puede ser más hondo: el constructo ontológico más primario está profundamente conectado con estas relaciones trinitarias. Naturalmente, la noción de la persona como suppositum de su particularidad, se lee con este instrumental.

La frase final, que corona el ascenso: «Ahora creemos haber llegado al arquetipo de estas diferentes formas de soporte y pensamos poder captarlas en relación a él y en relación mutua de unas con otras» (STEIN, 2002-2004e, p. 955). Salvado el salto ontológico, la formulación no puede ser más luminosa. Todos los entes, en su polaridad inescindible de forma vacía y contenido, se remiten a esta relación esencia divina - suppositum, que funciona a modo de arquetipo. Y aún más elocuente: la relación entre los mismos entes creados abreva de este arquetipo. Determinación última de la mismidad, en simultáneo con la socialidad que la constituye.

Subida al andarivel de la equivalencia analógica entre suppositum y forma vacía, Stein opera una "comunicación de idiomas" tremendamente fecunda, ya que refiriéndose a la relación de la persona divina con la esencia en cuanto arquetipo del fundamento de la individuación, arriba al despunte de una metafísica de la intersubjetividad que von Balthasar reclama con justa razón. ${ }^{16}$ ¿Por qué? La relación esencia divina — persona

\footnotetext{
16 "Una razón importante estriba en que la intersubjetividad sobre la que se funda la ética del evangelio no podía encontrar en el pensamiento clásico antiguo una fundamentación filosófica suficiente y ni siquiera hoy se ha llegado a constituirse realmente en tema capital de la filosofía cristiana. De este modo, la teología augustiniana de la caritas tiene como trasfondo conceptual una metafísica, en gran parte neoplatónica, por tanto no dialógica, a la que se remite retrospectivamente (en Bernardo y su escuela) también la teología benedictina de la caritas, mientras que lo franciscano primitivo es reinterpretado por Buenaventura a la luz de Agustín y Dionisio, el carisma dominico (...) se apoya en Aristóteles y, con Eckart, en Parménides; lo específicamente ignaciano en Suárez se repliega retrospectivamente hasta Escoto, pues su filosofía no guarda una unidad estrecha con los comentario de los Ejercicios. Se observa así que el pensamiento en su desarrollo histórico, no absorbe las inspiraciones de carácter cristiano, no trata de caminar a su lado, sino que las va revistiendo ocasionalmente con el inmenso arsenal especulativo ya existente", VON BALTHASAR,
}

Rev. Pistis Prax., Teol. Pastor., Curitiba, v. 8, n. 2, 211-243, maio/ago. 2016 
trinitaria no acontece en compartimientos estancos: cada persona con la misma esencia. En realidad no existe esencia fuera de la entrega recíproca de estas personas. Al punto de poder decir que en la continua comunicación inmanente, en virtud de la inmanencia recíproca que las caracteriza, lo que mutuamente se entregan es la misma divina esencia simple, una y perfecta. En este continuo vaciarse de sí para llenarse de las otras, llenarse de las otras vaciándose de sí, en perfecta simetría especular, actúan la intersubjetividad esencial en la kénosis esencial. Y así subsisten en-sí- fuera-de-sí-en-sí.

Aún cabe detenernos apenas un instante en la valencia arquetípica que ella otorga a la relación entre la esencia y personas (el núcleo de la categoría perijóresis) en Dios respecto de todas las otras formas (vacías) en su imbricamiento mutuo. Es aquí donde hemos de situar el hondo parentesco entre empatía y Trinidad: la perijóresis es la fuente arcana, primordial, arquetípica, modélica, fontal, primigenia de toda empatía humana y cósmica.

\section{Conclusión: el Dios empático como fuente, espacio y sustento de la comunión humana}

"El Dios visto, escuchado y tocado en el hombre Jesús es al mismo tiempo el hombre que ve, escucha y toca a Dios" (VON BALTHASAR, 1985, p. 86). La inclusión de la espléndida cita de von Balthasar en este apartado solo se justifica si tenemos en cuenta un dato hasta ahora ignorado en este artículo: la etimología de la Einfühlung en alemán, incluye una forma primitiva de conocimiento sensible, por tanteo. La osadía primera, la de un Dios empatizable y empatizante, parece encontrar su expresión máxima en la magistral fórmula Karl Rahner, el teólogo de Friburgo: en el hombre Jesús acontece el mutuo tantearse del hombre y Dios. Él mismo en su existencia encarnada, es el Dios empático. El encuentro personificado de dos movimientos: de Dios hacia el hombre, y del hombre hacia Dios. Y esto abre a un mundo de consideraciones novedosas, del que solo

H. U. Herrlichkeit. Eine theologische Ästhetik, Bd. III,1: Im Raum der Metaphysik:2. Neuzeit, Johannes Verlag, Einsiedeln 19613; tr. esp: Gloria. Una estética teológica. III/V, Encuentro, Madrid, 1996, 30. 
podemos balbucear algunas, a modo de conclusión que más que cerrar nos catapulta a un mundo de sentido por desentrañar.

La primera cuestión que emerge clara es que en la osada hipótesis del comienzo, la empatía nos permite zambullirnos en la vivencia única y desconcertante de un Dios que saliendo de sí, se hace uno de los nuestros y en su carne nos conoce y deja que lo conozcamos. El misterio arcano se devela en su cuerpo entregado. No hay vínculo real con Dios sino es a través de su carne, de su humanidad herida y resucitada. Y esa humanidad viviente, perforada por la necedad del pecado, es la portadora de la intimidad que nuestra existencia busca.

A decir verdad, los pasos de la coreografía empática pensados por Stein en sus albores, responden a la historia de la salvación en sus tres momentos fundamentales. Durante todo el Antiguo Testamento el diálogo entre Dios y su pueblo consistió en un lento reconocerse y "acostumbrarse" de ambos a la alteridad del otro. En este período el núcleo era la alianza, una y otra vez traicionada por el pueblo con su pecado de idolatría. La distancia de las vivencias primó hasta que la promesa de una presencia transfigurante irrumpió en su cumplimiento con la encarnación. En el hombre Jesús, Dios aprendió el ritmo y los códigos de su creatura. Se sumergió en su vivencia más abyecta que es el pecado hasta identificarse con él $(2$ Cor 5,21$)$ y suspenderse en la insólita epoché de la Pascua. Pero resucitado, y vuelta su humanidad a su divinidad que la transfigura, la ascensión se corresponde con el tercer paso empático en el que el hombre Dios vuelve a su Padre y nuestro Padre, pero llevándonos consigo en su cuerpo del que somos parte.

Esta circulación entre Él y el hombre se reactiva cada vez, que a modo de un nuevo pentecostés, su Espíritu, verdadero Nosotros divino, se nos transfunde irrigando su cuerpo de vida en abundancia. De aquí que quepa considerar la fe como una auténtica experiencia empática: de auténtica transferencia cruzada de vivencias entre Dios y el hombre en la carne de Cristo. Solo uno vio al Padre, pero su vivencia se transfiere en la medida en que Espíritu mediante, logramos sintonizar existencialmente con su experiencia neurálgica de amor que se manifiesta en la Pascua. Y como desde hace unas décadas, en el corazón de la experiencia de fe anida la mística entendida como auténtica vivencia del misterio, bien podemos 
asomarnos a la inhabitación recíproca entre el hombre y Dios en Cristo en términos perijoréticos. Amar en el corazón de Cristo Jesús, y vivir en Cristo, no es sino el movimiento responsivo a un Dios que no duda en hacernos más íntimos que nuestra más íntima intimidad. Su interioridad es nuestra tierra prometida, y la fe no será sino un permanente éxodo hacia el Padre. Pero en la carne. Siempre en la carne.

Y la carne-cuerpo del Crucificado Resucitado implicará inexcusablemente una dimensión social que Pablo asume en la imagen de la iglesia como cuerpo. Si la ontología de la comunidad mostraba la carencia de un yo en sentido estricto y la construcción social depende enteramente de los miembros que la conforman, en el caso eclesial es totalmente diverso. El Nosotros divino, el Espíritu, auténtica reciprocidad hispostática, ofrece el espacio y sustrato genuino para la comunión humana. Lo que se vislumbra en carácter arquetípico de la Empatía primordial respecto de la creada, solo se efectiviza en el diálogo libre de cada hombre o mujer con el Dios Trino que en Cristo se le ofrece como alimento.

\section{Referencias}

ALIGHIERI, D. Divina Comedia. Madrid: Cátedra, 1988.

BERTOLINI, A. Empatía y Trinidad en E. Stein. Fenomenología, teología y ontología en clave relacional. Salamanca: Secretariado trinitario, 2013.

CAMBÓN, E. Trinidad: modelo social. Madrid: Ciudad nueva, 2000.

CASTILLA DE CORTAZ, C. B. La complementariedad varón - mujer. Nuevas hipótesis. Madrid: Rialp, 2004.

CODA, P. Sul luogo della Trinità. Rileggendo il De Trinitate di Agostino. Roma: Città Nuova, 2008.

DISANDRO, C. Historia semántica de la pericóresis. Stud. Patr., v. 15, p. 441-447, 1984.

EGAN, J. Towards trinitarian perichoresis: Saint Gregory the Theologian. The Greek Orthodox Theological Review, v. 39, p. 83-93, 1994. 
FORD, H. Perichoresis and interpenetration: St. Taylor's Coleridge's trinitarian conception of unity. Theology, v. 89, p. 20-24, 1986.

GILSON, E. L'esprit de la philosophie médiévale. Paris: Vrin, 1948.

GRESHAKE, G. El Dios uno y Trino. Barcelona: Herder, 2001.

GUNTON, C. Unidad, Trinidad, Pluralidad. Salamanca: Sígueme, 2005.

PEMÁN, J. M. “Oración de la Luz" en CEA, Liturgia de las horas IV. Tiempo ordinario, Barcelona, 1997.

PEZZELLA, A. M. Edith Stein fenomenóloga. Roma: Pontificia Università Lateranense, 1995.

STEIN, E. Sobre el problema de la empatía, in Idem. Obras completas II, VictoriaMadrid-Burgos: Ediciones El Carmen-Editorial de Espiritualidad-Editorial Monte Carmelo, 2002-2004a.

STEIN, E. Individuo y Comunidad in Idem, Contribuciones a la fundamentación filosófica de la psicología y de las ciencias del espíritu, en Id., Obras completas II, Victoria-Madrid-Burgos: Ediciones El Carmen-Editorial de EspiritualidadEditorial Monte Carmelo, 2002-2004b.

STEIN, E. Fundamentos teóricos de la labor social de la educación, in Idem., Obras completas III, Victoria-Madrid-Burgos: Ediciones El Carmen-Editorial de Espiritualidad-Editorial Monte Carmelo, 2002-2004c.

STEIN, E. Vocación del hombre y de la mujer según el orden de la naturaleza y de la gracia, en Id., Obras completas III, Victoria-Madrid-Burgos: Ediciones El CarmenEditorial de Espiritualidad-Editorial Monte Carmelo, 2002-2004d.

STEIN, E. Ser finito y ser eterno, in Idem., Obras completas III, Victoria-MadridBurgos: Ediciones El Carmen-Editorial de Espiritualidad-Editorial Monte Carmelo, 2002-2004e.

STEIN, E. Potencia y acto, in Idem., Obras completas III, Victoria-Madrid-Burgos: Ediciones El Carmen-Editorial de Espiritualidad-Editorial Monte Carmelo, 2002-2004f. 
STEIN, E. Causalidad psíquica, in Idem. Contribuciones a la fundación filosófica de la psicología y de las ciencias del espíritu, Obras completas II, Victoria-MadridBurgos: Ediciones El Carmen-Editorial de Espiritualidad-Editorial Monte Carmelo, 2002-2004g.

VON BALTHASAR, H. U. Gloria I: La percepción de la forma. Madrid: Encuentro, 1985.

ZARAZAGA, G. Dios es comunión. El nuevo paradigma trinitario. Salamanca: Secretariado trinitario, 2004.

Recibido: 29/06/2016

Received: 29/06/2016

Aprovado: 15/08/2016 Approved: 08/15/2016 
